\title{
Etanercept attenuates traumatic brain injury in rats by reducing early microglial expression of tumor necrosis factor- $\alpha$
}

\author{
Chung-Ching Chio ${ }^{1 \dagger}$, Chin-Hong Chang ${ }^{1+}$, Che-Chuan Wang ${ }^{1}$, Chong-Un Cheong ${ }^{2}$, Chien-Ming Chao ${ }^{3}$, \\ Bor-Chih Cheng ${ }^{1,5}$, Chung-Zhing Yang ${ }^{5}$ and Ching-Ping Chang ${ }^{4^{*}}$
}

\begin{abstract}
Background: Tumor necrosis factor-alpha (TNF-a) is elevated early in injured brain after traumatic brain injury (TBI), in humans and in animals. Etanercept (a TNF-a antagonist with anti-inflammatory effects) attenuates TBI in rats by reducing both microglial and astrocytic activation and increased serum levels of TNF-a. However, it is not known whether etanercept improves outcomes of TBI by attenuating microglia-associated, astrocytes-associated, and/or neurons-associated TNF-a expression in ischemic brain. A well clinically relevant rat model, where a lateral fluid percussion is combined with systemic administration of etanercept immediately after TBI, was used. The neurological severity score and motor function was measured on all rats preinjury and on day 3 after etanercept administration. At the same time, the neuronal and glial production of TNF-a was measured by Immunofluorescence staining. In addition, TNFa contents of ischemic cerebral homogenates was measured using commercial enzyme-linked immunosorbent assay kits.
\end{abstract}

Results: In addition to inducing brain ischemia as well as neurological and motor deficits, TBI caused significantly higher numbers of microglia-TNF-a double positive cells, but not neurons-TNF-a or astrocytes-TNF-a double positive cells in the injured brain areas than did the sham operated controls, when evaluated 3 days after TBI. The TBl-induced cerebral ischemia, neurological motor deficits, and increased numbers of microglia-TNF-a double positive cells and increased TNF-a levels in the injured brain were all significantly attenuated by etanercept therapy.

Conclusion: This finding indicates that early microglia overproduction of TNF-a in the injured brain region after TBI contributes to cerebral ischemia and neurological motor deficits, which can be attenuated by etanercept therapy. Studies in this model could provide insight into the mechanisms underlying neurological motor disturbance in brain-injured patients.

Keywords: Traumatic brain injury, Microglia, Tumor necrosis factor-alpha, Astrocyte, Neuron

\section{Background}

Tumor necrosis factor-alpha (TNF- $\alpha$ ) is elevated in both the serum and cerebrospinal fluid of humans after traumatic brain injury (TBI) [1,2]. It is also elevated 1 to 4 hours after injury in clinically relevant models of TBI such as lateral fluid-percussion injury (FPI) [3-5]. The

\footnotetext{
* Correspondence: jessica.cpchang@gmail.com

${ }^{\dagger}$ Equal contributors

${ }^{4}$ Department of Biotechnology, Southern Taiwan University of Science and

Technology, Tainan, Taiwan

Full list of author information is available at the end of the article
}

overproduction of TNF- $\alpha$ caused by TBI can be significantly attenuated by blockade of TNF- $\alpha$ synthesis or activity [6-8]. However, the cellular sources of this early elevation of TNF- $\alpha$ remain unclear. Evidence has indicated that TNF- $\alpha$ is predominantly expressed by neurons [7] or microglia $[9,10]$ in the injured brain.

Etanercept is a TNF antagonist with anti-inflammatory effects. Systemic administration at the dosage of $5 \mathrm{mg} / \mathrm{kg}$ of body weight improves outcomes of TBI in rats by reducing microglial and astrocytic activation and activated inflammation (e.g., increased serum levels of TNF- $\alpha$ ) [8]. Again, it is not known whether etanercept improves

\section{Biomed Central}


outcomes of TBI in rats by reducing microglia-associated, astrocytes-associated and/or neurons-associated TNF- $\alpha$ expression in ischemic brain.

We explored these two questions by studying the interrelationship between the activation of microgliaTNF- $\alpha$, astrocyte-TNF- $\alpha$, and neuron-TNF- $\alpha$ double labeling cells in the ischemic brain areas and the development of cerebral ischemia and neurological and motor dysfunction as well as the attenuating of cerebral ischemia and neurological and motor dysfunction by etanercept therapy after TBI.

\section{Methods}

\section{Animals}

Male Sprague-Dawley rats (280-300 g), obtained from the Animal Resource Center of the Taiwan National Science Council, were housed four per group at an ambient temperature of $22 \pm 1^{\circ} \mathrm{C}$ with a 12-h light-dark cycle. Pelleted rat chow and tap water were available ad libitum. All protocols, designed to minimize discomfort in the animals during surgery and in the recovery period, were approved by the Institutional Animal Care and Use Committee of Southern Taiwan University of Science and Technology.

\section{Surgery}

The rats were anesthetized with sodium pentobarbital (25 mg/kg, intraperitoneally [i.p.]; Sigma Chemical, St. Louis, MO, USA) and a mixture containing ketamine (4.4 mg/ kg, intramuscularly [i.m.]; Nankuang Pharmaceutical, Tainan, Taiwan), atropine $(0.02633 \mathrm{mg} / \mathrm{kg}$, [i.m.]; Sintong Chemical, Taoyuan City, Taiwan), and xylazine (6.77 mg/kg, [i.m.]) (Bayer AG, Leverkusen, Germany). Both the femoral artery and vein on the right side were cannulated with PE50 polyethylene tubing to monitor blood pressure and analyze blood gas respectively. After cannulation, the wound was sutured and the rats were placed in a stereotaxic frame. Each rat's scalp was sagittally incised, and then the rat was subjected to a FPI $[11,12]$. Prior to FPI, a 4.8-mm circular craniotomy was performed midway between the lambda and bregma skull points
$3.0 \mathrm{~mm}$ to the right of the central suture. A modified Luer-Lock connector (trauma cannula) (2.6 mm inner diameter) was secured into the craniotomy with cyanoacrylate adhesive and dental acrylic. Subsequently, the FPI was induced by a pressure (severe intensity: amplitude of $2.2 \mathrm{~atm}$ ospheres) delivered by a fluid percussion device (Virginia Commonwealth University Biochemical Engineering, Richmond, VA, USA). The rat was removed from the device with the acrylic removed, and the incision sutured. Each injured and sham-injured animal for the FPI model was housed individually and closely evaluated for behavioral recovery immediately after the FPI. During the surgical procedure, mean arterial pressure, heart rate, and core temperature were continuously monitored for indicating depth of anesthesia.

\section{Experimental procedures}

The rats $(n=96)$ were randomly allocated into the following groups: 1) FPI+saline control group $(n=32)$ : rats were subjected to FPI plus a dose of normal saline $(1 \mathrm{ml} / \mathrm{kg}$ body weight [i.p.]) once every $12 \mathrm{~h}$ for 3 consecutive days [8]; 2) FPI+etanercept group $(\mathrm{n}=32)$ : this group was subjected to FPI plus etanercept (5 mg/kg body weight [i.p.]) once per $12 \mathrm{~h}$ for 3 consecutive days; and 3) untreated Sham group $(\mathrm{n}=32)$ : rats were subjected to the same surgical procedures as the other two groups, but were not given a FPI. The injection volume was the same for both saline and etanercept groups. The sham-group was untreated.

In experiment 1 , etanercept (5 $\mathrm{mg} / \mathrm{kg}$ [i.p.]) $(\mathrm{n}=8)$ or saline $(1 \mathrm{ml} / \mathrm{kg}$ [i.p.]) $(\mathrm{n}=8)$ was randomly administrated immediately after FPI, and their effects on neurological motor performance were assessed preinjury and on 4 days post-FPI. Another 8 untreated sham-operated rats were used as controls. Etanercept (ENBREL ${ }^{\mathrm{TM}}$ Wyeth Laboratories, Hampshire, UK) was reconstituted with normal saline according to the manufacturer's instructions.

In experiment 2, three days after FPI, immediately following the neurological motor tests, all the rats used in experimental 1 were killed 3 days after FPI for brain contusion assessment.

Table 1 Antibodies used for Immunofluorescence staining

\begin{tabular}{|c|c|c|c|c|c|}
\hline Antibody & Antigen & Host & Company & Catalog\# & Dilution \\
\hline \multicolumn{6}{|l|}{ Primary antibody } \\
\hline NeuN & neuron & mouse & Abcam & ab104224 & $1: 200$ \\
\hline GFAP & astrocyte & mouse & Abcam & ab4648 & $1: 200$ \\
\hline Iba-1 & microglia & mouse & Abcam & ab15690 & $1: 200$ \\
\hline TNF-a & TNF-a & goat & Santa Cruz & SC-1351 & $1: 50$ \\
\hline \multicolumn{6}{|c|}{ Secondary antibody (conjugation) } \\
\hline Mouse IgG (Alexa Fluor 568) & Mouse $\lg G$ & goat & Invitrogen & A11031 & $1: 400$ \\
\hline Goat-IgG (DyLight 488) & Goat lgG & donkey & Abcam & ab96931 & 1:400 \\
\hline
\end{tabular}


In experiment 3 , etanercept $(5 \mathrm{mg} / \mathrm{kg}$ [i.p.] $(\mathrm{n}=8)$ or saline $(1 \mathrm{ml} / \mathrm{kg}$ [i.p.] $(\mathrm{n}=8)$ was randomly given to each rat immediately after FPI once every $12 \mathrm{~h}$ for 3 consecutive days, and the effect on the number of the colocalization of TNF- $\alpha$ and microglia specific marker cells, TNF- $\alpha$ and neurons specific marker cells, and TNF- $\alpha$ and astrocyte specific marker cells in the cortex, white matter, hippocampus, or hypothalamus was determined. Untreated sham group, FPI+saline group, and FPI-etanercept group were killed $72 \mathrm{~h}$ post-FPI ( $\mathrm{n}=8$ for each group) for immunohistological evaluation.

In experiment 4 , untreated sham group $(n=8)$, FPI+saline group $(\mathrm{n}=8)$, and FPI+etanercept group $(\mathrm{n}=8)$

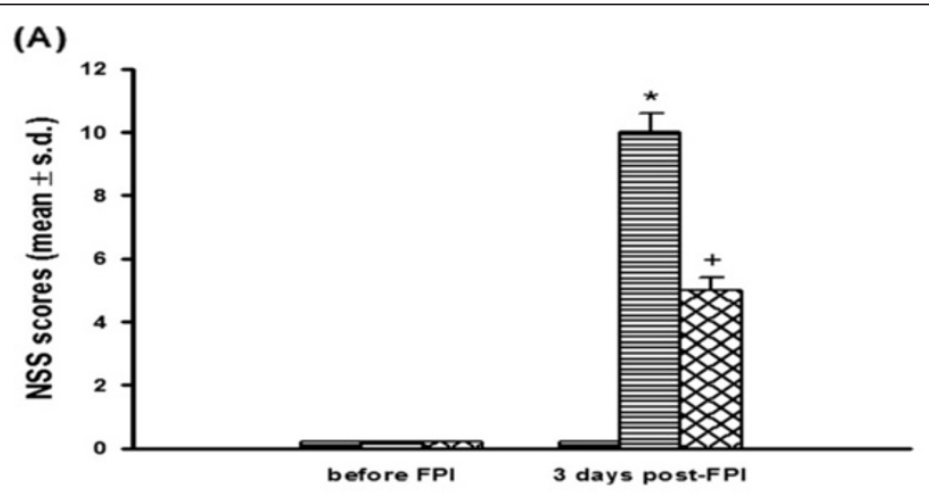

(B)
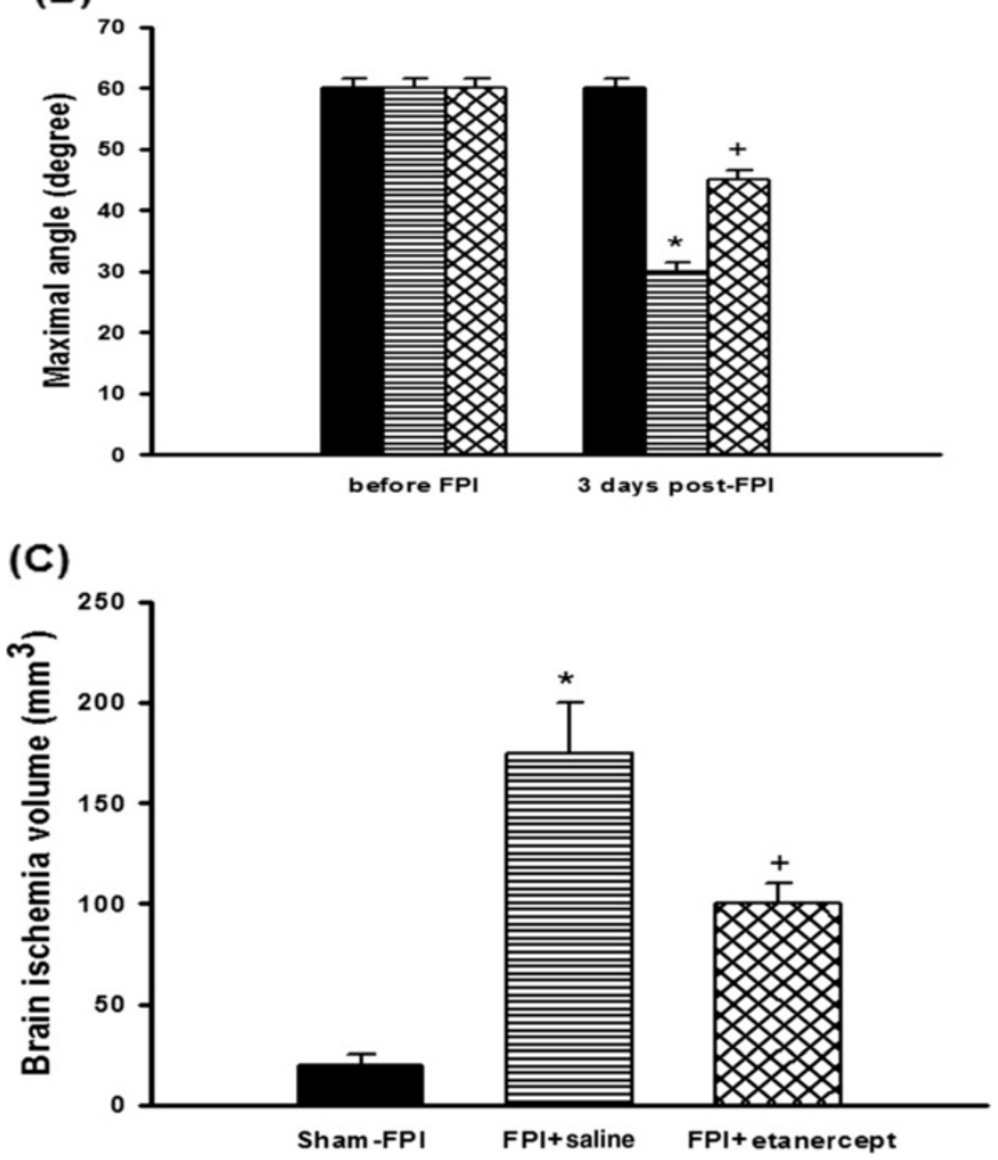

Figure 1 Etancercept attenuated FPI-induced increased neurological severity scores (NSS) (A), decreased motor performance (B), and increased brain ischemic volume (C). *The FPI+saline group (目; $n=8$ ) showed a significant increase in NSS ( $P<0.01$ ), a significant decrease in maximal angle $(P<0.05)$, and a significant increase in brain ischemic volume $(P<0.05)$ compared with the untreated sham-operated group $(\mathbf{\square})$ 3 days post-FPI. ${ }^{+}$The $\mathrm{FPI}+$ etanercept group ( $\mathrm{n}=8$ ) showed a significant decrease in NSS $(\mathrm{P}<0.05)$, a significant increase in maximal angle $(\mathrm{P}<0.05)$, and a significant decrease in brain ischemia volume $(\mathrm{P}<0.05)$ compared with the FPI+saline group (目; $\mathrm{n}=8)$. 
animals were killed $72 \mathrm{~h}$ post-FPI for determination of TNF- $\alpha$ protein level in ischemic brains.

\section{Neurological function evaluation}

Acute neurological injury was assessed in all rats on the day prior to and on 3 days after surgery using a neurological severity score (NSS) [13]. NSS is a composite of the motor (muscle status, abnormal movement), sensory (visual, tactile and proprioceptive) and reflex tests. One point was given for failure to perform a task. Thus, the higher score, the more severe is injury, with a maximum of 14 points. The NSS was measured on all rats pre injury and on day 3 after etanercept administration.

The inclined plane was used to measure limb strength [14]. The rat was placed, facing right and then left, perpendicular to the slope of a $20 \times 20-\mathrm{cm}$ ruffed surface of an inclined plane starting at an angle of $55^{\circ}$. The angle was increased or decreased in $5^{\circ}$ increments to determine the maximal angle at which a rat could hold to the plane. The data for each day were the mean of the left- and right-side maximal angles. All behavioral tests were examined and independently scored by two observers who were unaware of what treatment the rats had been given. These scores were averaged to arrive at one score for each rat for the behavioral session. The rats were tested pre injury and on day 3 after etanercept administration.

\section{TNF- $a$ content of ischemic cerebral homogenate}

Cerebral hemispheres were quickly dissected free and kept on ice in physiological salt solution $(\mathrm{mM}: \mathrm{NaCl}$ 119; $\mathrm{KCl}$ 4.7; MgSO4 1.17; KH2PO4 1.18; $\mathrm{NaHCO}_{3} 25$; EDTA 0.026; and $\mathrm{CaCl} 22.5)$ containing $5 \mathrm{mM}$ glucose. Segments of cerebral cortex (75 mg i.e., approximately the weight of each cerebral hemisphere) were weighted, cut into small pieces, dispersed by aspiration into a pipette and suspended in $1 \mathrm{ml}$ of physiological salt solution in a test tube. Samples were kept on wet ice for $20 \mathrm{~min}$ before use. The homogenates were centrifuged at 7,500

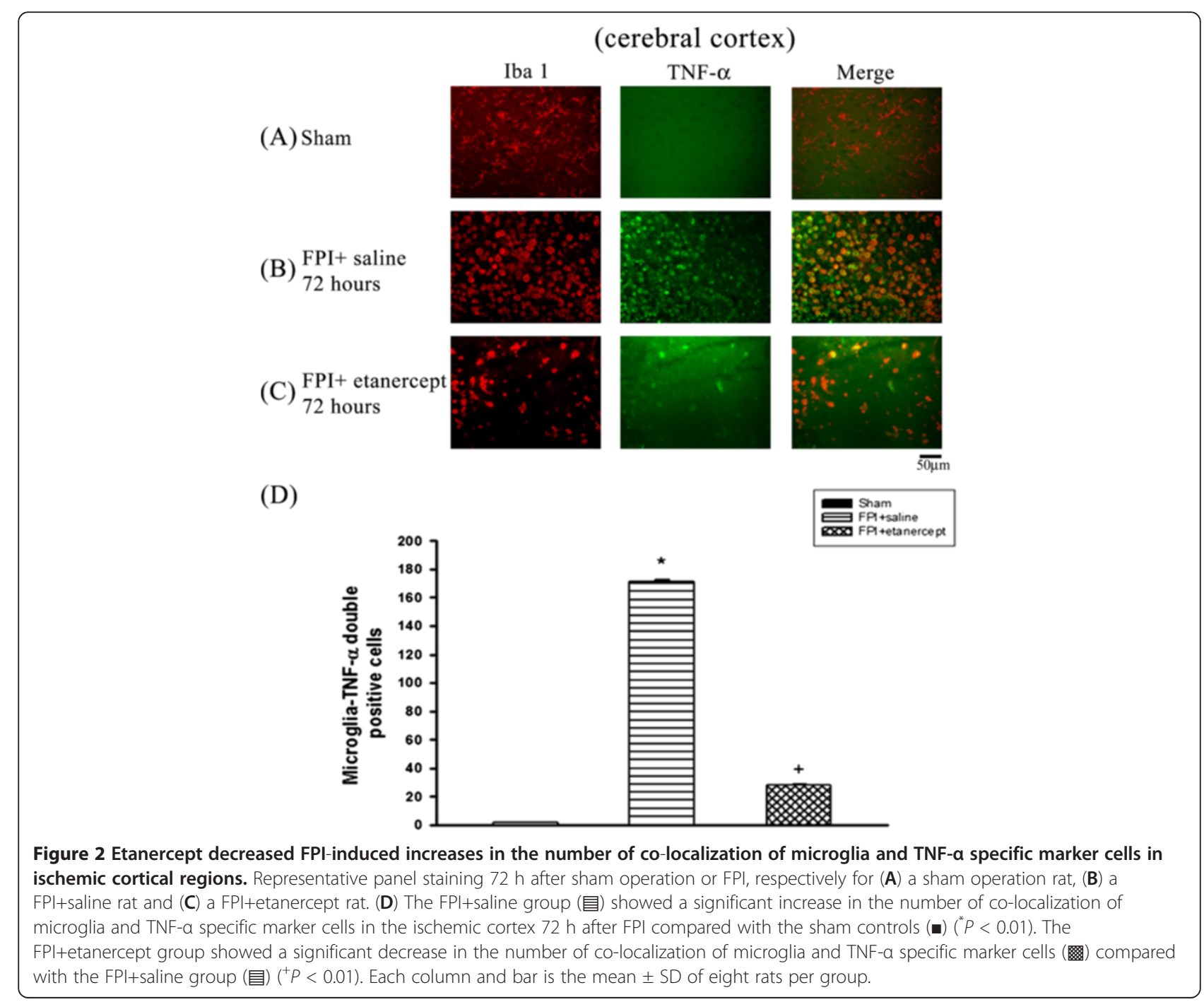


rpm $(5,150 \times g)$ for $20 \mathrm{~min}$. The supernatants were used for measuring TNF- $\alpha$ concentrations. TNF- $\alpha$ concentrations were measured using commercial enzyme-linked immunosorbent assay (ELISA) kits (Biosource International Inc. Boshide Company, Wuhan, China) and following the manufacturer's instructions. The minimum detectable concentrations of TNF- $\alpha$ were $1.1 \mathrm{pg} / \mathrm{ml}$. There was no cross-reactivity reported with other cytokines. All samples were assayed is duplicate.

\section{Cerebral ischemia assay}

The triphenyltetrazolium chloride (TTC) staining procedures are described elsewhere [15]. Three days after they had undergone FPI, all the rats were deeply anesthetized (sodium pentobarbital, $100 \mathrm{mg} / \mathrm{kg}$ [i.p.]) and then perfused intracardially with saline. Their brain tissue was then removed, immersed in cold saline for $5 \mathrm{~min}$, and sliced into 2.0-mm sections with a tissue slicer. The brain slices were incubated in 2\% TTC dissolved in phosphate buffer saline (PBS) for $30 \mathrm{~min}$ at $37^{\circ} \mathrm{C}$ and then transferred to $5 \%$ formaldehyde solution for fixation. The volume of ischemia, revealed by negative TTC stains that indicated dehydrogenase-deficient tissue, was measured in each slice and summed using computerized planimetry (PC-based Image Tools Software). The volume of ischemia was calculated as $2 \mathrm{~mm}$ (thickness of the slice) $\times$ [sum of the ischemia area in all brain slices $\left.(\mathrm{mm})^{2}\right]$.

\section{Immunohistological determination}

Serial $50-\mu \mathrm{m}$ sections corresponding to coronal coordinates $0.8 \mathrm{~mm}$ to $5.3 \mathrm{~mm}$ posterior to the bregma were incubated in $2 \mathrm{~mol} / \mathrm{L} \mathrm{HCL}$ for $30 \mathrm{~min}$, rinsed in $0.1 \mathrm{~mol} / \mathrm{L}$ boric acid $(\mathrm{pH}$ 8.5) for $3 \mathrm{~min}$ at room temperature and then incubated with primary antibodies in phosphate-buffered saline (PBS) containing 0.5\% normal bovine serum at $4^{\circ} \mathrm{C}$ overnight; secondary

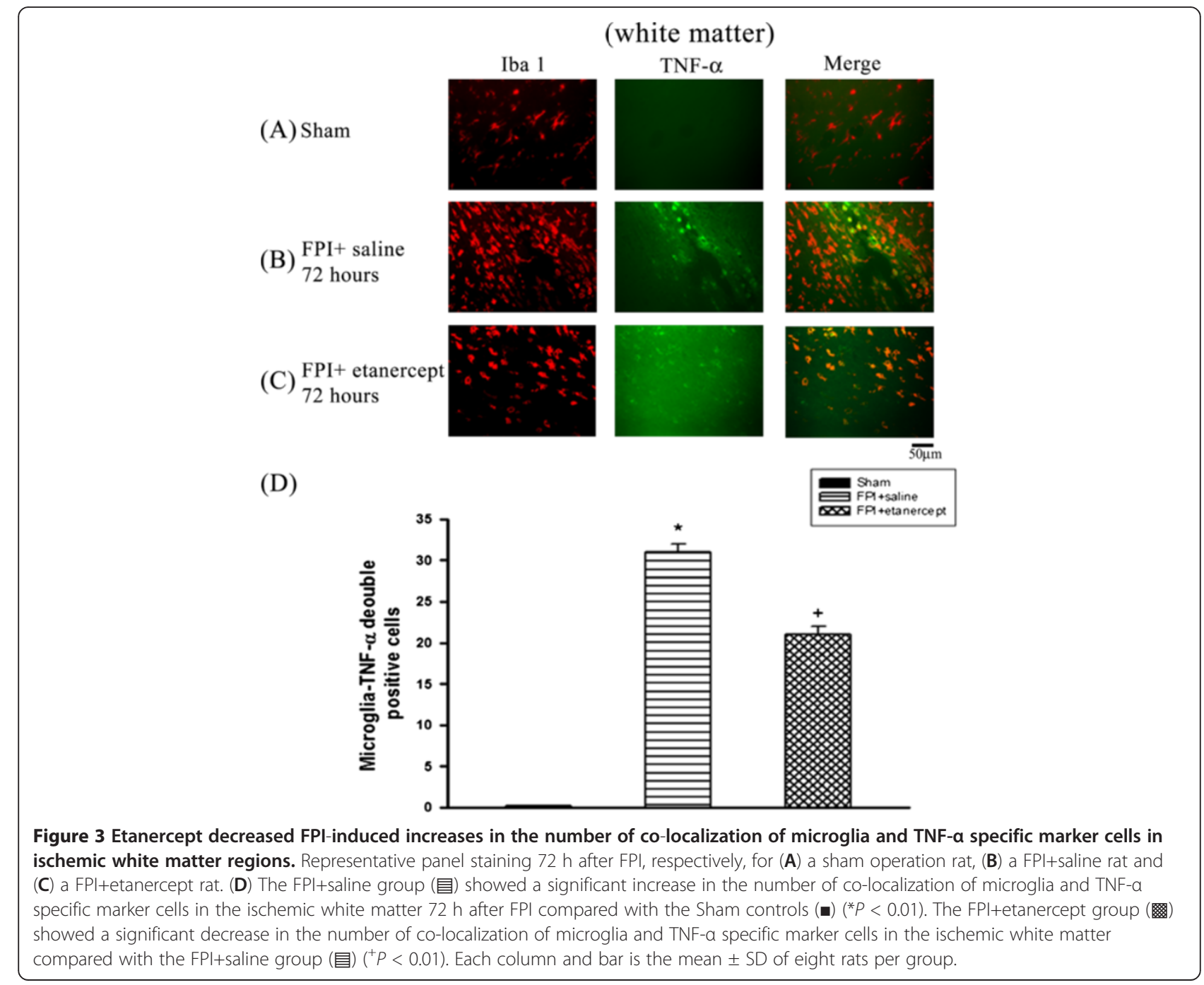


antibodies-incubated for $1 \mathrm{~h}$ at room temperature. The antibodies therein were, sequentially, mouse monoclonal anti-NeuN (Abcan, 1:200), mouse monoclonal antiGFAP antibody (Abcam, 1:200), mouse monoclonal anti-Iba-1 antibody (Abcam, 1:200), goat polyclonal antiTNF- $\alpha$ antibody (Santa Cruz, 1:50), DyLight 488conjugated donkey-anti-goat IgG antibody (Abcam, 1:400), and Alexa Fluro 568-conjugated donkey anti-mouse IgG antibody (Invitrogen, 1:400). The sections were coverslipped with the mounting medium (fluorescent mounting medium; Dako). The labeled cells were calculated in 5 coronal sections from each rat and expressed as the mean number of cells per section. For negative controls sections, all the procedures were without the primary antibody. Primary and secondary antibodies for multiple-staining are listed in Table 1.

Images of the fluorescent immunohistochemistry for immune cells were captured at 100x magnification using a fluorescence microscope system (Zeiss Axiovision; Zeiss Gmbh, Göttingen, Germany), and images from bregma $-0.8,-1.5,-2.5,-3.0$, and $-3.5 \mathrm{~mm}$ from each animal were evaluated. In each image, immune-positive cells showing staining with a cellular morphology and above background level were manually and exhaustively counted using the Axiovision image analysis software (Zeiss Gmbh), All cell counts were performed by an investigator (C. P.C.) blinded to the treatment status of each animal.

\section{Statistical analysis}

The data are presented as mean \pm standard deviation (SD). A repeated measures analysis of variance was used to test the treatment-by-time interactions and the effect of treatment over time on each score. Duncan's multiple range test was used for post hoc multiple comparisons among means. Analyses for all behavioral variables used Student's unpaired t-test to compare variables between

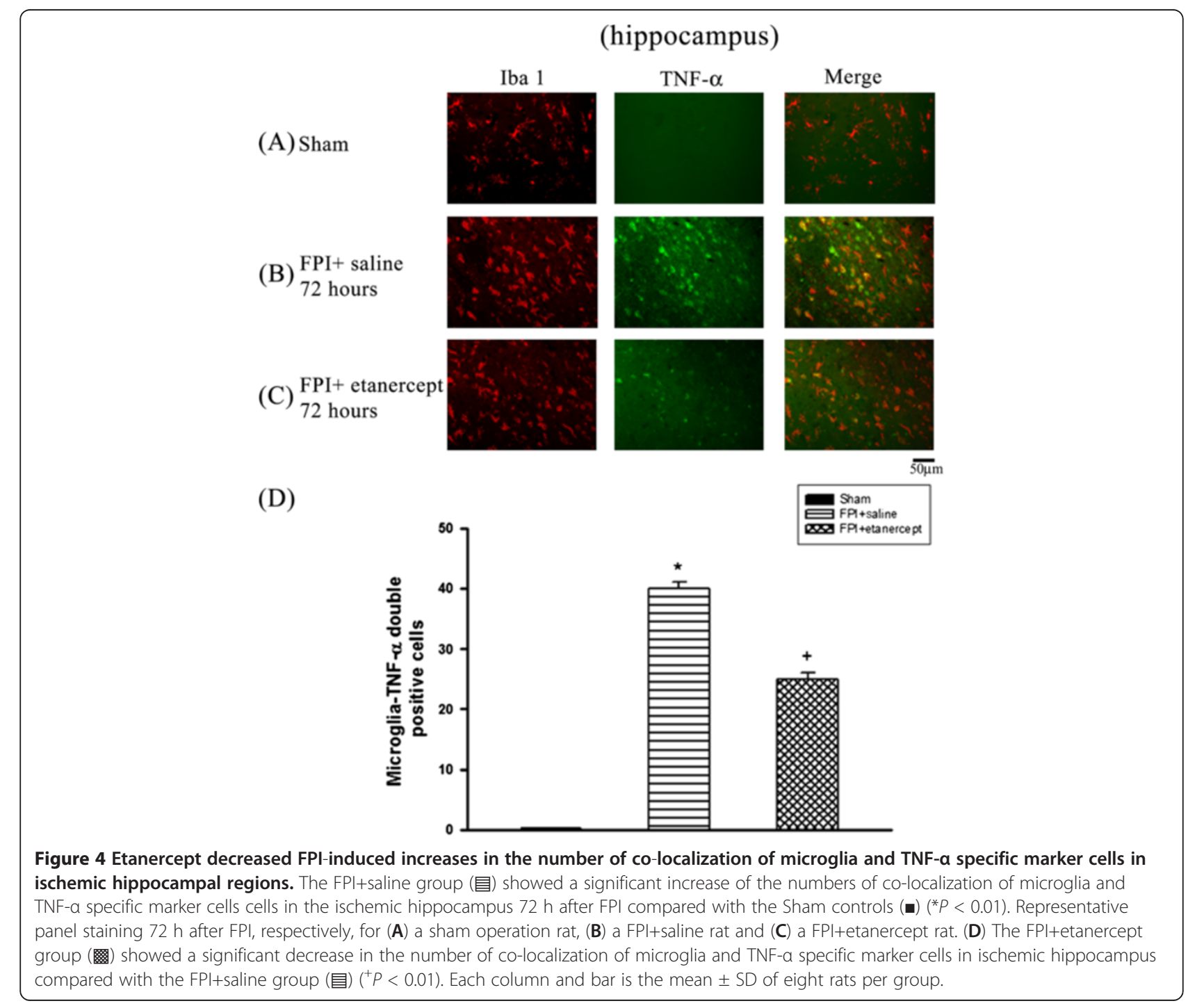


groups. Bonferroni's analysis was then performed when appropriate, to determine post-hoc significance at individual time point. Data was analyzed using Statistica, Software $^{\circledR}$ and, in all cases, statistical significance was set at $\mathrm{P}<0.05$.

\section{Results}

\section{Acute effects of FPI}

The average intensity of the fluid pulse delivered to animals in the injured group was $2.24 \pm 0.05$ atm (mean \pm SEM). Immediately following this impact, all rats experienced a period of apnea (lasting approximately $25 \mathrm{sec}$ ), hypertension (approximately up to $\sim 140 \mathrm{mmHg}$ and lasting $\sim 25 \mathrm{sec}$ ), and tachycardia ( $\sim 390$ beats/min and lasting more than 120 minutes). Sham-injured animals showed no apnea, hypertension, or tachycardia. There was no difference between 2 treatment groups.
FPI caused neurological and motor dysfunction, which etanercept attenuated

Three days after the rats had been subjected to FPI, behavioral tests revealed that the NSS of both the (FPI+saline) group and the (FPI+etanercept) group were significantly $(\mathrm{P}<0.05)$ higher than those of the untreated sham-FPI group (10 or 5 vs $0 ; n=8$ for each) (Figure 1A). However, compared with those of the (FPI+saline) group, the the NSS values of the (FPI +etanercept) group $(\mathrm{n}=8)$ were significantly $(\mathrm{P}<0.05)$ lower. In contrast, motor function tests showed that the maximal angles of the (FPI+saline) group were significantly $(\mathrm{P}<0.05)$ lower than those of the shamFPI group $\left(60^{\circ} \mathrm{Vs} 30^{\circ} ; \mathrm{n}=8\right.$ for each) (Figure 1B). Compared with those of the $(\mathrm{FPI}+$ saline) group, the maximal degrees were significantly $(\mathrm{P}<0.05)$ higher in the (FPI+etanercept) group $\left(30^{\circ} \mathrm{Vs} 45^{\circ} ; \mathrm{n}=8\right.$ for each) (Figure 1B).

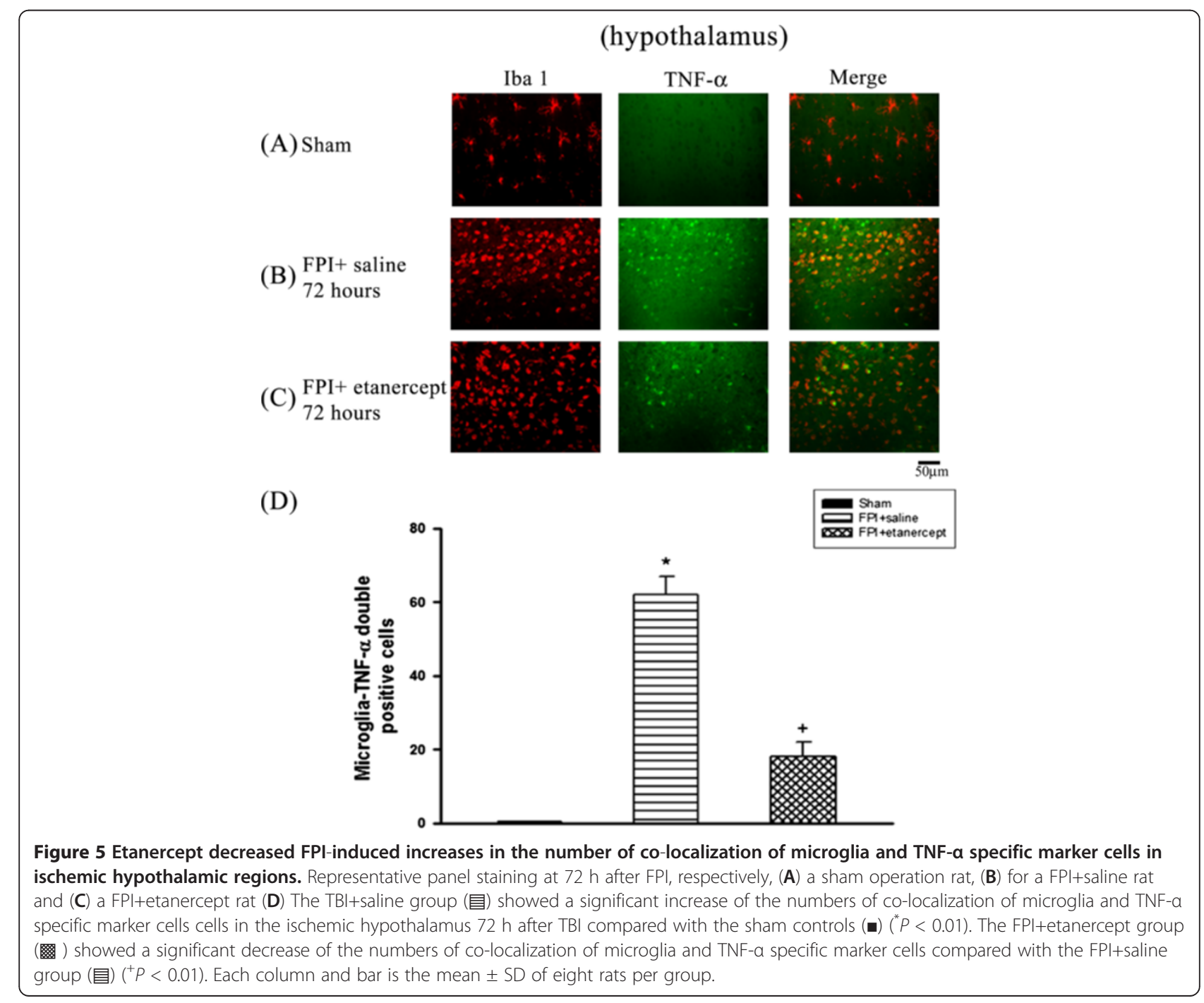


FPI induced cerebral ischemia, which etanercept attenuated

TTC staining showed that the (FPI+saline) group had significantly $(\mathrm{P}<0.001)$ larger areas of brain ischemia than did the sham-FPI group (Figure 1C). (186 \pm 26 $\mathrm{mm}^{3}$ vs $21 \pm 5 \mathrm{~mm}^{3} ; \mathrm{n}=8$ for each group). The cerebral ischemia areas were significantly $(\mathrm{P}<0.01)$ smaller in the FPI+etanercept group than in the FPI+saline group $\left(104 \pm 12 \mathrm{~mm}^{3}\right.$ vs $186 \pm 26 \mathrm{~mm}^{3} ; \mathrm{n}=8$ for each group) (Figure 1C).

FPI caused the microglial production of TNF- $a$, which etanercept attenuated

Immunofluorescence staining revealed that the number of colocalization of microglia and TNF- $\alpha$ specific markers in the ischemic cortex (Figure 2), white matter (Figure 3), and hippocampus (Figure 4) and hypothalamus (Figure 5) were significantly higher $(\mathrm{P}<0.01)$ in the $\mathrm{FPI}+$ saline group than in the sham group, when evaluated $72 \mathrm{~h}$ after the start of FPI. Nevertheless, compared with those of the saline-treated FPI group, the etanercept-treated FPI rats had significantly $(\mathrm{P}<0.01)$ lower values of the numbers of co-localization of microglia and TNF- $\alpha$ specific markers in the ischemic cortex (Figure 2), white mater (Figure 3), hippocampus (Figure 4), and hypothalamus (Figure 5).

On the other hand, numbers of the co-localization of TNF- $\alpha$ and neurons specific marker cells (Figure 6A) or TNF- $\alpha$ and astrocytes specific marker cells (Figure 7) in the ischemic cortex of the saline-treated or the etanercept-treated FPI groups were not significantly different $(P>0.01)$ from the sham group when evaluated 72 hours after FPI or sham operation.

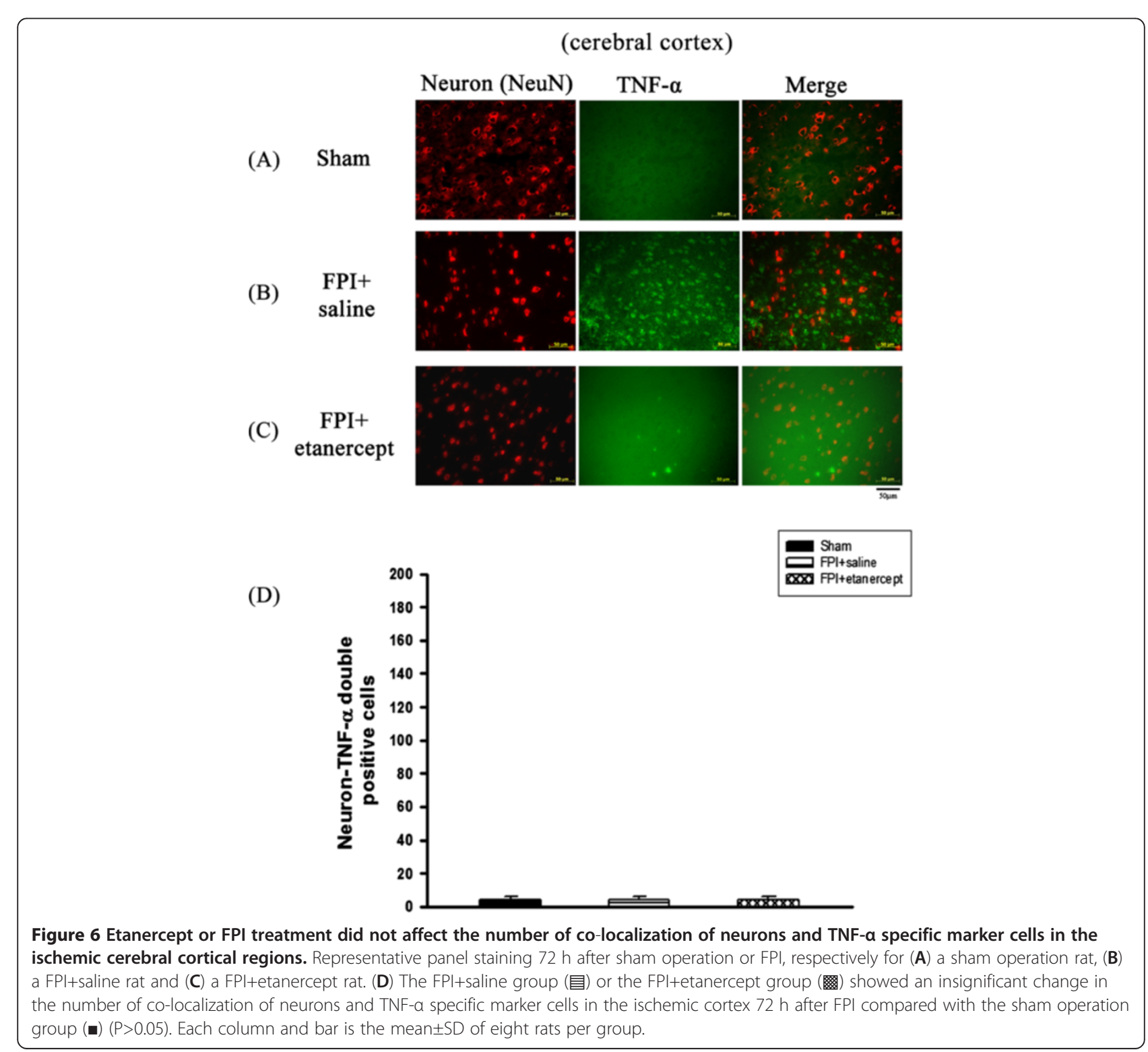




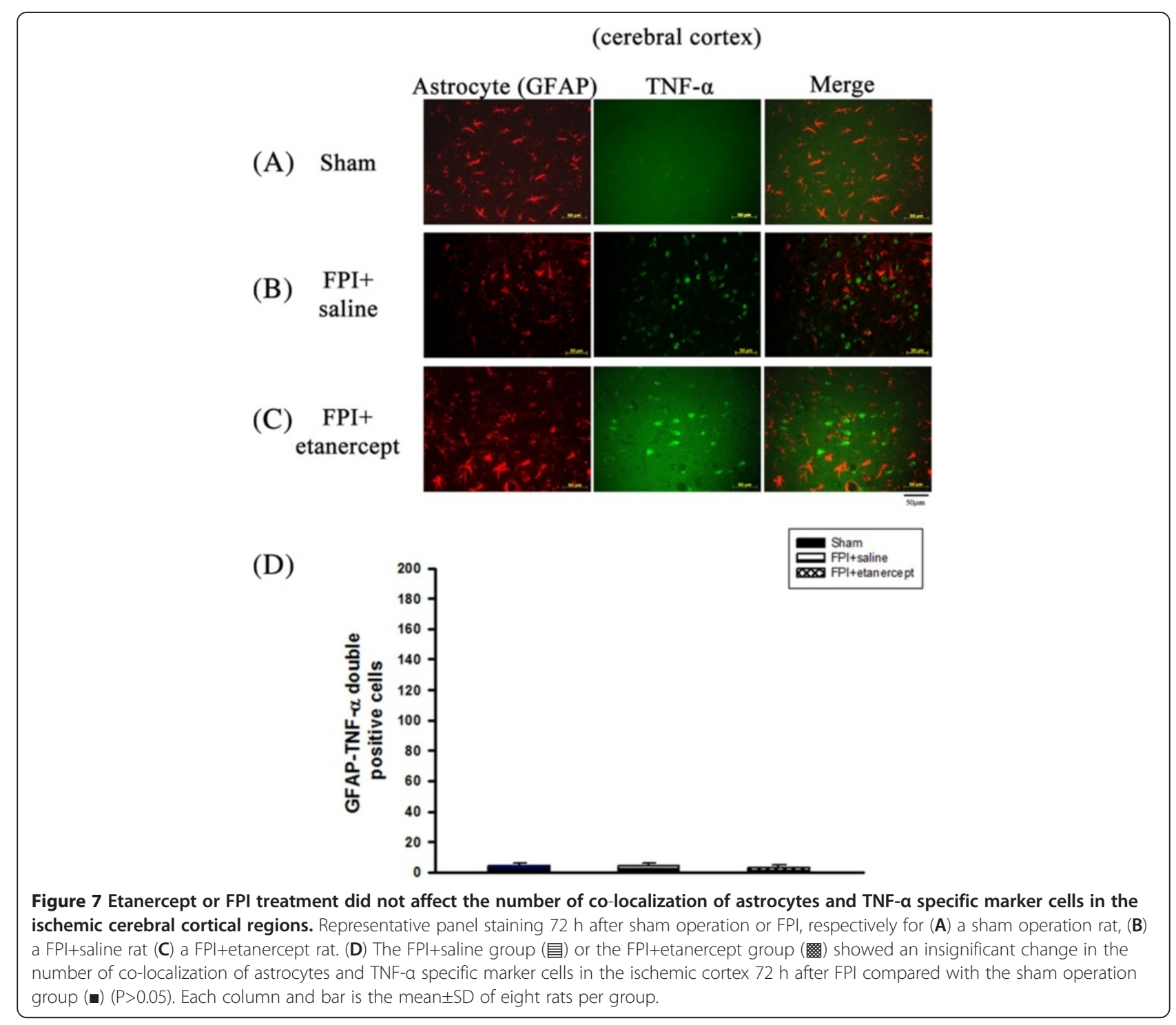

\section{FPI caused overproduction of cerebral TNF-a, which etanercept attenuated}

The cerebral levels of TNF- $\alpha$ were consistently significantly $(\mathrm{P}<0.05)$ higher for the FPI+saline and the FPI +etanercept groups than for the sham group $72 \mathrm{~h}$ after FPI or sham operation (Figure 8), but significantly lower in the FPI+etanercept group than in the FPI+saline group.

\section{Discussion}

The major findings of our present study are: (1) etanercept injected systemically reduces motor and neurological deficits caused by FPI by day 3 after FPI; (2) the increased numbers of the co-localization of TNF- $\alpha$ and microglia specific marker cells are significantly and selectively higher in the ischemic cortex, white matter, hippocampus, and hypothalamus during
FPI which can be attenuated by etanercept therapy; (3) overproduction of cerebral TNF- $\alpha$ in the ischemic cortex caused by FPI can be attenuated by etanercept; (4) by day 3 after FPI, neither the co-localization of TNF- $\alpha$ and astrocyte specific marker cells nor the TNF- $\alpha$ and neuron specific marker cells can be seem in the ischemic brain regions. Our data suggest that systemic administration of etanercept may improve outcome of FPI by attenuating the activation of microglial TNF- $\alpha$ in the ischemic brain. The hypothesis is in part supported by many investigations. For example, Li and Colleagues [16] has reported that TNF- $\alpha$ is significantly higher in the lesion boundary zone in the saline-treated rats by 3 days after FPI. Cerebral inflammation in response to trauma, stroke, and seizure is characterized by the activation of resident microglia [17-19]. Activated microglia proliferate, change morphology by assuming an amoeboid shape, increase 


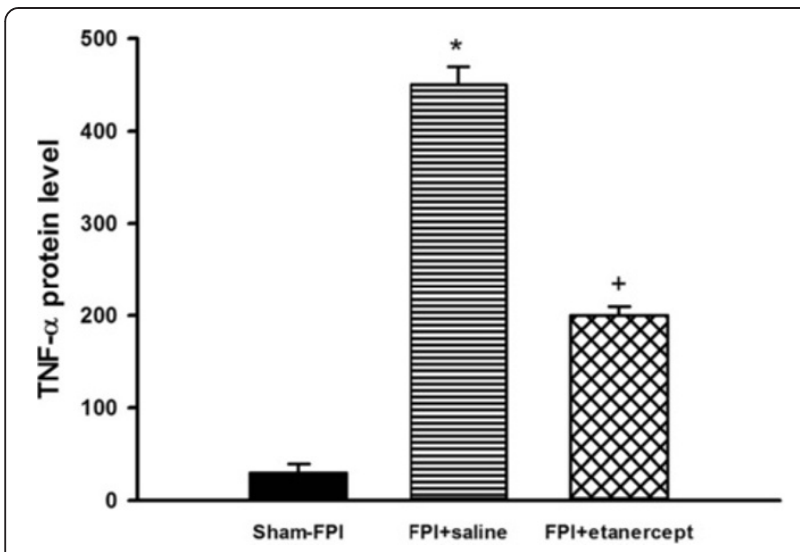

Figure 8 Etanercept attenuated TBI-induced increased brain levels of TNF-a. ${ }^{*}$ The FPI+saline group (冒; $\mathrm{n}=8$ ) showed a significant increase in ischemic cortical levels of TNF-a $(P<0.01)$ compared with the untreated sham-FPI group (घ). ${ }^{+}$The FPI+etanercept group 网; $n=8$ ) showed a significant decrease in the ischemic cortical levels of TNF-a $(P<0.05)$ compared with the FPI+saline group (目; $n=8)$.

phagocytosis, upregulate MHC class I molecules, and release cytokines [20,21].

TNF- $\alpha$ transduces death- and survival-signaling through its cognate receptors TNFR1 and TNFR2 and is involved in the inflammatory response following TBI [22-25]. Increases in TNF- $\alpha$ and other cytokines have been reported in cerebrospinal fluid and plasma samples in TBI patients [2,26-29]. Several groups [3,5,30-34] have reported increased TNF- $\alpha$ and other cytokine levels $1 \mathrm{~h}$ post-TBI, and peak levels $4 \mathrm{~h}$ post-TBI, after which, levels returned toward baseline. In Knoblach et al., [31], a secondary lesser increase at $72 \mathrm{~h}$ post-TBI was also reported. Furthermore, Holmin and Mathiesen [32] reported persistent elevations 4 days to 3 months after TBI, and Li et al., [16] found that TNF- $\alpha$ and other cytokines were significantly higher in the lesion boundary zone in saline-treated TBI rats 3 days post-TBI. In our rat model, microglial overproduction of TNF- $\alpha$ in several ischemic brain regions 3 days after TBI was also reported. In particular, Knoblch et al. [31] reported peak levels of TNF- $\alpha$ very early after TBI (1-4 hours) with localization to neurons, whereas our present results showed the peak levels of TNF- $\alpha$ occurred at 72 hours and were localized to the microglial cells. Thus, it appears that the cellular sources of this early elevation of TNF- $\alpha$ may be time-dependent. However, the most important point is that this elevated post-TBI TNF- $\alpha$ production in brain tissues can be significantly attenuated by etanercept therapy.

Accumulated evidence shows that TNF- $\alpha$ and its receptor play an important role in the pathophysiology of TBI $[22,24,25]$. In contrast, some evidence suggests that TNF- $\alpha$ plays a neuroprotective role following TBI $[35,36]$. Although TNF- $\alpha$ contributes to neuro-anatomical plasticity as well as an improvement of locomotor activity during recovery process [37], present data indicate that TNF- $\alpha$ is associated with the pathological effects as well as neurological motor deficits during acute phase after TBI. In the present study, despite the etanercept treatment there is still a robust TNF- $\alpha$ release post-injury. However, etanercept should be given only at acute phase [35,36]. A greater dose of etanercept administered during recovery process would not improve outcome and even exacerbate the pathological effects of TBI.

Etanercept, when administered systemically at the dosage approved for its licensed indications $(\sim 50 \mathrm{mg} /$ week in human), would not be expected to achieved therapeutic levels in the cerebrospinal fluid because of its high molecular weight [38]. It should be mentioned that the etanercept doses used in the present set-up are far higher than the normal subcutaneous dose used for rheumatoid arthritis. Administration of a dose in humans might result in significant penetration of etanercept into the cerebrospinal fluid; particularly in an experimental setting such as TBI, in which the blood- cerebrospinal fluid barrier might be damaged.

The present study focuses mainly the effects of etanercept on microglial overproduction of TNF- $\alpha$ in the rat brain effected by TBI. Actually, in addition to TNF- $\alpha$, TBI-induced increased levels of both interleukin-1 $\beta$ and interleukin- 6 were all significantly reduced by etanercept treatment [8]. Additionally, Iba1 stain was chosen as a marker of activated microglia. Stains for surveillance microglia would help clarify if etanercept interferes with microglia activation and/or interferes with chemokines production and subsequent migration of microglia to the contused/ischemic areas of the brain. Furthermore, it is possible that the beneficial effects of etanercept during TBI are a result of limiting macrophage recruitment in part [39].

It should be mentioned that in the present study, there appears to be quite a few instances of Iba1 and TNF- $\alpha$ labeling that do not coincide and the staining morphology is quite different in some instances (mor elongated Iba1 staining versus round/amoeboid TNF- $\alpha$ staining). Furthermore, Iba1 is not a particularly distinguishing cell-specific marker for microglia in the injured brain as infiltrating macrophages also express this antigen. In addition, although our present study showed that the sham-group displayed no evidence of damage 3 days post-FPI, Jones et al. [12] did display evidence of damage one month post-FPI. The discrepancy between our results and their findings could be due to time difference.

Finally, it should be mentioned that given that the sham animals in the present study did not receive injections on any treatment the authors might comment on the possible confound that the stress associated with the injections may have had on the TBI group versus sham. 


\section{Conclusion}

The present study demonstrates that TBI, in addition to inducing cerebral contusion and neurological motor deficits, cause the microglial overproduction of TNF- $\alpha$ in the injured cortex, hippocampus, white matter, and hypothalamus. The TBI-induced neurological motor deficits and microglial overproduction of TNF- $\alpha$ can be significantly attenuated by the post-TBI application of etanercept. Our data identify a role for the microglial production of TNF- $\alpha$ in the outcomes of TBI in rats. Etanercept may attenuate cerebral contusion and neurological motor deficits during TBI by inhibiting the activation of the microglia-TNF- $\alpha$ double positive cells in the ischemic brain region.

\section{Competing interests}

The authors declare that they have no competing interests.

\section{Authors' contributions}

CCC and CPC designed and conducted most of the experiments. CHC, CCW, CUC, CMC, BCC, CZY designed and conducted some of the experiments. CCC and CPC wrote most of the manuscript. All authors analyzed the data, revised the manuscript and gave final approval for publication.

\section{Acknowledgements}

This study was funded in part by the Taiwan National Science Council (NSC98-2314-B-218-MY2, NSC99-2314-B-384-004-MY3, NSC100-2314-B-218001, NSC101-2314-B-218-001-MY3), and the Taiwan Department of Health Center of Excellence for Clinical Trials and Research in Neuroscience (DOH99TD-B-111-003).

\section{Author details}

${ }^{1}$ Department of Surgery, Chi Mei Medical Center, Tainan, Taiwan.

${ }^{2}$ Department of Intensive Care Medicine, Chi-Mei Medical Center, Liouying, Tainan, Taiwan. ${ }^{3}$ Department of Surgery and Department of Intensive Care Medicine, Chi-Mei Medical Center, Liouying, Tainan, Taiwan. ${ }^{4}$ Department of Biotechnology, Southern Taiwan University of Science and Technology, Tainan, Taiwan. ${ }^{5}$ The PhD Program for Cancer Biology and Drug Discovery, College of Medical Science and Technology, Taipei Medical University, Taipei, Taiwan.

Received: 8 November 2012 Accepted: 7 March 2013

Published: 15 March 2013

\section{References}

1. Goodman JC, Robertson CS, Grossman RG, Narayan RK: Elevation of tumor necrosis factor in head injury. J Neuroimmunol 1990, 30(2-3):213-217.

2. Ross SA, Halliday MI, Campbell GC, Byrnes DP, Rowlands BJ: The presence of tumour necrosis factor in CSF and plasma after severe head injury. $\mathrm{Br}$ J Neurosurg 1994, 8(4):419-425.

3. Taupin V, Toulmond S, Serrano A, Benavides J, Zavala F: Increase in IL-6, IL1 and TNF levels in rat brain following traumatic lesion. Influence of preand post-traumatic treatment with Ro5 4864, a peripheral-type ( $p$ site) benzodiazepine ligand. J Neuroimmunol 1993, 42(2):177-185.

4. Yakovlev AG, Faden Al: Molecular biology of CNS injury. J Neurotrauma 1995, 12(5):767-777.

5. Fan L, Young PR, Barone FC, Feuerstein GZ, Smith DH, Mclntosh TK: Experimental brain injury induces differential expression of tumor necrosis factor-alpha mRNA in the CNS. Brain Res Mol Brain Res 1996, 36(2):287-291.

6. Shohami E, Gallily R, Mechoulam R, Bass R, Ben-Hur T: Cytokine production in the brain following closed head injury: dexanabinol (HU-211) is a novel TNF-alpha inhibitor and an effective neuroprotectant. $J$ Neuroimmunol 1997, 72(2):169-177.

7. Knoblach SM, Faden Al: Interleukin-10 improves outcome and alters proinflammatory cytokine expression after experimental traumatic brain injury. Exp Neurol 1998, 153(1):143-151.
8. Chio CC, Lin JW, Chang MW, Wang CC, Kuo JR, Yang CZ, Chang CP: Therapeutic evaluation of etanercept in a model of traumatic brain injury. J Neurochem 2010, 115(4):921-929.

9. Bezzi P, Volterra A: A neuron-glia signalling network in the active brain. Curr Opin Neurobiol 2001, 11(3):387-394.

10. Perry SW, Dewhurst S, Bellizzi MJ, Gelbard HA: Tumor necrosis factor-alpha in normal and diseased brain: Conflicting effects via intraneuronal receptor crosstalk? J Neurovirol 2002, 8(6):611-624.

11. Mclntosh TK, Noble L, Andrews B, Faden Al: Traumatic brain injury in the rat: characterization of a midline fluid-percussion model. Cent Nerv Syst Trauma 1987, 4:119-134.

12. Jones NC, Cardamone L, Williams JP, Salzberg MR, Myers D, O'Brien TJ: Experimental traumatic brain injury induces a pervasive hyperanxious phenotype in rats. J Neurotrauma 2008, 25(11):1367-1374.

13. Shohami $E$, Novikov M, Bass R: Long-term effect of HU-211, a novel noncompetitive NMDA antagonist, on motor and memory functions after closed head injury in the rat. Brain Res 1995, 674(1):55-62.

14. Chang MW, Young MS, Lin MT: An inclined plane system with microcontroller to determine limb motor function of laboratory animals. J Neurosci Methods 2008, 168(1):186-194.

15. Wang Y, Lin SZ, Chiou AL, Williams LR, Hoffer BJ: Glial cell line-derived neurotrophic factor protects against ischemia-induced injury in the cerebral cortex. J Neurosci 1997, 17(11):4341-4348.

16. Li B, Mahmood A, Lu D, Wu H, Xiong Y, Qu C, Chopp M: Simvastatin attenuates microglial cells and astrocyte activation and decreases interleukin-1 beta level after traumatic brain injury. Neurosurgery 2009, 65(1):179-185. discussion 185-186.

17. Dirnagl U, ladecola C, Moskowitz MA: Pathobiology of ischaemic stroke: an integrated view. Trends Neurosci 1999, 22(9):391-397.

18. Feuerstein $\mathrm{G}$, Wang $\mathrm{X}$, Barone FC: Cytokines in brain ischemia-the role of TNF alpha. Cell Mol Neurobiol 1998, 18(6):695-701.

19. Minghetti L, Levi G: Microglia as effector cells in brain damage and repair: focus on prostanoids and nitric oxide. Prog Neurobiol 1998, 54(1):99-125.

20. Batchelor PE, Liberatore GT, Wong JY, Porritt MJ, Frerichs F, Donnan GA, Howells DW: Activated macrophages and microglia induce dopaminergic sprouting in the injured striatum and express brain-derived neurotrophic factor and glial cell line-derived neurotrophic factor. J Neurosci 1999, 19(5):1708-1716.

21. Hanisch UK: Microglia as a source and target of cytokines. Glia 2002, 40(2):140-155

22. Bermpohl D, You Z, Lo EH, Kim HH, Whalen MJ: TNF alpha and Fas mediate tissue damage and functional outcome after traumatic brain injury in mice. J Cereb Blood Flow Metab 2007, 27(11):1806-1818.

23. Maier B, Lehnert M, Laurer HL, Mautes AE, Steudel WI, Marzi I: Delayed elevation of soluble tumor necrosis factor receptors p75 and p55 in cerebrospinal fluid and plasma after traumatic brain injury. Shock 2006, 26(2):122-127.

24. Neumann H, Schweigreiter R, Yamashita T, Rosenkranz K, Wekerle $H$, Barde YA: Tumor necrosis factor inhibits neurite outgrowth and branching of hippocampal neurons by a rho-dependent mechanism. J Neurosci 2002, 22(3):854-862.

25. Williams AJ, Wei HH, Dave JR, Tortella FC: Acute and delayed neuroinflammatory response following experimental penetrating ballistic brain injury in the rat. J Neuroinflammation 2007, 4:17.

26. Bell MJ, Kochanek PM, Doughty LA, Carcillo JA, Adelson PD, Clark RS, Wisniewski SR, Whalen MJ, DeKosky ST: Interleukin-6 and interleukin-10 in cerebrospinal fluid after severe traumatic brain injury in children. J Neurotrauma 1997, 14(7):451-457.

27. Csuka E, Morganti-Kossmann MC, Lenzlinger PM, Joller H, Trentz O, Kossmann $\mathrm{T}: \mathrm{IL}-10$ levels in cerebrospinal fluid and serum of patients with severe traumatic brain injury: relationship to IL-6, TNF-alpha, TGF-beta1 and blood-brain barrier function. J Neuroimmuno/ 1999, 101(2):211-221.

28. Holmin S, Soderlund J, Biberfeld P, Mathiesen T: Intracerebral inflammation after human brain contusion. Neurosurgery 1998, 42(2):291-298. discussion 298-299.

29. McClain C, Cohen D, Phillips R, Ott L, Young B: Increased plasma and ventricular fluid interleukin-6 levels in patients with head injury. J Lab Clin Med 1991, 118(3):225-231.

30. Holmin S, Schalling M, Hojeberg B, Nordqvist AC, Skeftruna AK, Mathiesen T: Delayed cytokine expression in rat brain following experimental contusion. J Neurosurg 1997, 86(3):493-504. 
31. Knoblach SM, Fan L, Faden Al: Early neuronal expression of tumor necrosis factor-alpha after experimental brain injury contributes to neurological impairment. J Neuroimmunol 1999, 95(1-2):115-125.

32. Shohami E, Novikov M, Bass R, Yamin A, Gallily R: Closed head injury triggers early production of TNF alpha and IL-6 by brain tissue. J Cereb Blood Flow Metab 1994, 14(4):615-619.

33. Stahel PF, Shohami E, Younis FM, Kariya K, Otto VI, Lenzlinger PM, Grosjean MB, Eugster HP, Trentz O, Kossmann T, others: Experimental closed head injury: analysis of neurological outcome, blood-brain barrier dysfunction, intracranial neutrophil infiltration, and neuronal cell death in mice deficient in genes for pro-inflammatory cytokines. J Cereb Blood Flow Metab 2000, 20(2):369-380.

34. Stover JF, Schoning B, Beyer TF, Woiciechowsky C, Unterberg AW: Temporal profile of cerebrospinal fluid glutamate, interleukin-6, and tumor necrosis factor-alpha in relation to brain edema and contusion following controlled cortical impact injury in rats. Neurosci Lett 2000, 288(1):25-28.

35. Scherbel U, Raghupathi R, Nakamura M, Saatman KE, Trojanowski JQ, Neugebauer E, Marino MW, McIntosh TK: Differential acute and chronic responses of tumor necrosis factor-deficient mice to experimental brain injury. Proc Natl Acad Sci U S A 1999, 96(15):8721-8726.

36. Shohami E, Ginis I, Hallenbeck JM: Dual role of tumor necrosis factor alpha in brain injury. Cytokine Growth Factor Rev 1999, 10(2):119-130. Review.

37. Oshima T, Lee S, Sato A, Oda S, Hirasawa H, Yamashita T: TNF-alpha contributes to axonal sprouting and functional recovery following traumatic brain injury. Brain Res 2009, 1290:102-110

38. Francis J, Chu Y, Johnson AK, Weiss RM, Felder RB: Acute myocardial infarction induces hypothalamic cytokine synthesis. Am J Physiol Heart Circ Physiol 2004, 286(6):H2264-H2271.

39. Bao F, Fleming JC, Golshani R, Pearse DD, Kasabov L, Brown A, Weaver LC: A selective phosphodiesterase-4 inhibitor reduces leukocyte infiltration, oxidative processes, and tissue damage after spinal cord injury. J Neurotrauma 2011, 28(6):1035-1049.

doi:10.1186/1471-2202-14-33

Cite this article as: Chio et al.: Etanercept attenuates traumatic brain injury in rats by reducing early microglial expression of tumor necrosis factor- $\alpha$. BMC Neuroscience 2013 14:33.

\section{Submit your next manuscript to BioMed Central and take full advantage of:}

- Convenient online submission

- Thorough peer review

- No space constraints or color figure charges

- Immediate publication on acceptance

- Inclusion in PubMed, CAS, Scopus and Google Scholar

- Research which is freely available for redistribution 